\title{
Production of Eco-Friendly Concrete Masonry Units Using Powder Waste Glass
}

\author{
Roz-Ud-Din Nassar ${ }^{1, *}$, Danish Saeed ${ }^{2}$, Muhammad Sufyan-Ud-Din ${ }^{3}$, Shumayal Nassar $^{3}$ \\ ${ }^{1}$ Department of Civil and Infrastructure Engineering at American University of Ras Al Khaimah (AURAK), United Arab Emirates \\ ${ }^{2}$ Khwaja Fareed UEIT Rahim Yar Khan, Pakistan \\ ${ }^{3}$ Department of Civil Engineering at American University of Sharjah, United Arab Emirates
}

Received December 2, 2021; Revised January 17, 2022; Accepted February 16, 2022

\section{Cite This Paper in the following Citation Styles}

(a): [1] Roz-Ud-Din Nassar, Danish Saeed, Muhammad Sufyan-Ud-Din, Shumayal Nassar, "Production of Eco-friendly Concrete Masonry Units Using Powder Waste Glass," Civil Engineering and Architecture, Vol. 10, No. 2, pp. 415-424, 2022. DOI: 10.13189/cea.2022.100202.

(b): Roz-Ud-Din Nassar, Danish Saeed, Muhammad Sufyan-Ud-Din, Shumayal Nassar (2022). Production of Eco-friendly Concrete Masonry Units Using Powder Waste Glass. Civil Engineering and Architecture, 10(2), 415-424. DOI: $10.13189 /$ cea.2022.100202.

Copyright $\odot 2022$ by authors, all rights reserved. Authors agree that this article remains permanently open access under the terms of the Creative Commons Attribution License 4.0 International License

\begin{abstract}
This article investigates the use of powder waste glass (PWG) as partial replacement of cement for the production of Concrete Masonry Units (CMU) using a lab experimental program. Initially, an optimum level of partial replacement of cement with PWG was determined in the preliminary experimental tests on mortar mixtures incorporating PWG. Mixtures with $100 \%$ cement were also produced for comparison with the PWG modified mixtures. Test results of the main experimental program confirmed the viability of $15 \mathrm{wt} . \%$ replacement of cement with fine PWG having median particle size of $18 \mu \mathrm{m}$ towards production of CMU with enhanced strength and durability attributes. The use of PWG as partial replacement cement benefitted the later-age strength and durability of the resulting cementitious mixture. At 56 and 90 days of ages, the PWG mixture-based CMU achieved about $12 \%$ higher strength than that of control CMU. Furthermore, eight-day cumulative water sorption of PWG-based CMU was recorded to be $43 \%$ less than that of normal CMU. Similarly, a $10 \%$ reduction in the dry density of the hardened CMU produced with PWG was recorded in comparison to that of control CMU produced with $100 \%$ cement. The inclusion of PWG as partial replacement of cement was observed to increase the initial and final setting times and slightly reduce the flow characteristic of the resulting cementitious mixtures. The use of PWG for the production of CMU blocks is viewed as an excellent practice for the production of strong, durable, light,
\end{abstract}

economical and eco-friendly masonry construction.

Keywords Concrete Masonry Units, Powder Waste Glass, Strength, Durability, Economy

\section{Introduction}

Masonry is an ancient and one of the most popular methods of construction, which is still used for the construction of various types of low- rise structures $[1,2]$. In addition to the traditional burnt clay bricks, CMU have been extensively used as the building blocks of a masonry structures. These include the structures made of load-bearing and non-load bearing masonry walls. Over the years, the use of CMU as masonry building units has taken over traditional clay bricks mainly due to their energy efficient production, lower $\mathrm{CO}_{2}$ emission during manufacturing, enhanced durability and better surface finishing as compared to the burnt clay bricks [3-5]. In 2020, approximately 62.13 million square meters of concrete blocks were produced in the UK [6]. The US production was estimated to be 522.6 billion masonry units by the end of 2020. It has been forecasted that the global concrete block and brick manufacturing shall reach 2.3 Trillion by the end of 2027 at a growth rate of $2.4 \%$ during the 2020-2027 period [7]. 
In spite of the popularity of the use of CMU in masonry construction, its overall production has considerable carbon footprints and is regarded as an energy-intensive production similar to the production of other cementitious products involving the use of Portland cement [8-12]. This attribute is brought about by the emission of about 0.9 tonne of $\mathrm{CO}_{2}$ associated with the production of each tonne of Portland cement $[13,14]$. Besides, the production of Portland cement is highly energy-intensive being third to the production of aluminum and steel production among the common construction materials $[4,15]$. The construction industry is going to face the challenge of increasing demand for built-infrastructure in the coming years as the world population has been estimated to reach 9.7 billion by the year 2050 [16]. This will translate into huge demand of construction materials including cement products such as concrete and CMU which eventually will result into a significant increase in cement production, resulting into more complicated environmental issues arising from its production. It is therefore urgently required to devise strategies meant to mitigate the damaging environmental effects of cement production. Although the global cement industry has taken considerable measures to reduce the carbon emissions from cement production and enhance the energy efficiency of its production. These include; lowering the direct $\mathrm{CO}_{2}$ intensity of cement (tonne of carbon dioxide per tonne of cement $\left[\mathrm{tCO}_{2} / \mathrm{t}\right.$ cement $]$ ) to 0.52 , lowering the thermal energy intensity of clinker (gigajoule per tonne of clinker [GJ/t clinker]) to 3.3 from the exiting value of 3.5 , and reducing the clinker to cement ratio to 0.64 from the existing ratio of $0.65[17,18]$. However, much needs to be done on urgent basis in this regard.

Researchers have suggested various approaches to bring the current construction industry practices within the fold of sustainable, environmentally-friendly, and energy efficient developments. These include the use of various industrial and agriculture wastes as partial replacement of cement and / or aggregate for the production of concrete, mortar, and CMU [8, 19-22]; use of low carbon energy sources [5]; consumption of less cement in concrete mixtures by specifying later age strengths as the required design strengths [23], and using cement of higher strength class in concrete and mortar mixtures [24]. Out of these a number of studies have reported the effectiveness of the use of waste materials for the manufacture of various cementitious formulations $[9,10,15,25,26]$. Waste glass which forms part of the municipal solid waste stream, when reduced to powder size has been identified to be a viable partial replacement of cement for production of concrete [27-29]. The suitability of PWG for use in concrete as partial replacement of cement is dual: firstly; a huge quantity waste glass is annually produced worldwide. Alone in U.S. the production of waste glass was estimated to be 12.3 million tons in 2018 which works out to $4.2 \%$ of all municipal solid waste [30]. Huge part of this waste glass can be consumed in concrete in the form of PWG as partial replacement of cement [31-34]. Secondly; the use of PWG results in significant enhancement of the strength and durability attributes of the resulting concrete mixtures [35-37]. Both aspects associated with the use of PWG in concrete shall result into an economical and durable concrete production which is environmentally friendly, as well.

Although a significant number of studies exist on the use of traditional supplementary cementitious materials (SCM) for the production of CMU, this study evaluates the use of PWG as an SCM in the cementitious mixture for the manufacturing of CMU. The suitability of the PWG containing cementitious mixture for the production of CMU has been experimentally investigated from the standpoint of strength, durability, and economy of the units and resulting masonry structure. Based on the results of preliminary lab tests, a $15 \mathrm{wt} \%$ replacement of cement with PWG has been chosen to be the optimum for the production of CMU.

\section{Materials and methods}

\subsection{Materials}

PWG having physical properties as shown in Table 1 was used as 15 wt.\% replacement of cement for the production of CMU. Type-I Portland cement conforming to ASTM C-150, fine aggregate having fineness modulus of 2.75, and tap water were used for the production of the PWG and control mixtures in the experimental program. Figure 1 shows the particle size distribution of PWG and cement, while Table 2 presents the chemical composition of the two materials.

Table 1. Physical properties of PWG

\begin{tabular}{cccc}
\hline $\begin{array}{c}\text { Specific } \\
\text { gravity }\end{array}$ & $\begin{array}{c}\text { Specific } \\
\text { surface area }\end{array}$ & $\begin{array}{c}\text { Median } \\
\text { particle } \\
\text { size }\end{array}$ & $\begin{array}{c}\text { Moisture } \\
\text { content }\end{array}$ \\
\hline $2.43 \mathrm{~g} / \mathrm{cm}^{3}$ & $4885 \mathrm{~cm}^{2} / \mathrm{g}$ & $18 \mu \mathrm{m}$ & $0.12 \%$ \\
\hline
\end{tabular}




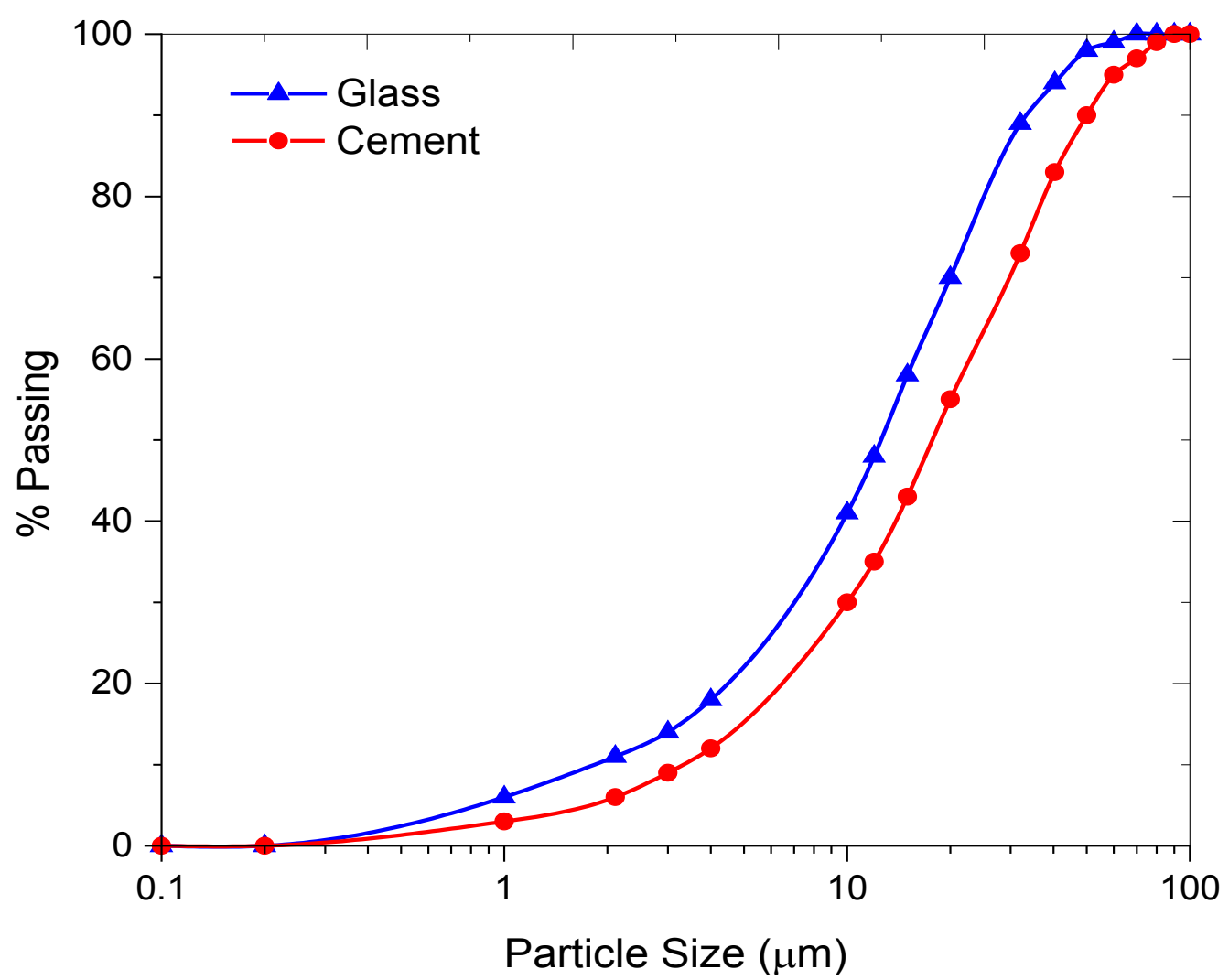

Figure 1. Particle size distribution of glass and cement

\subsection{Methodology}

\subsubsection{Preliminary Mortar Mixtures}

Based on the given physical and chemical characteristics of the PWG, it was necessary to ascertain a suitable level of cement replacement with PWG. Consequently, in order to determine the optimum PWG content in the CMU mixtures, preliminary mixture designs were produced with 1:2.75 cement to sand ratio having water to cement ratio of 0.47 . In these mixtures cement was replaced with PWG at 15 and 25 wt.\%. These mixtures were evaluated in terms of their compressive strengths at 1,7 , and 28 days of mixture ages. For each of the mixture design two replicates were tested. Each of the test result represents an average of three test readings. Based on these test results, mixture designs were formulated for the production of CMU in the main testing program.

\subsubsection{Specimens Preparation}

Cube mortar specimens having the size of $50 \mathrm{~mm}$ of the preliminary mixtures were produced to carry out compressive strength test of these mixtures according to the guidelines of ASTM C-109. Figure 2 shows the view of some of the mortar cubes produced in the preliminary testing. These specimens were water cured in the lab until their age of testing. Hollow CMU shown in Figure 3, having the size of $40 \mathrm{~cm}$ (length) $\times 20 \mathrm{~cm}$ (width) $\times 19.5 \mathrm{~cm}$ (height), area of $430 \mathrm{~cm}^{2}$, face shell thickness of $3 \mathrm{~cm}$, and web thickness of $2.85 \mathrm{~cm}$ were produced with normal and PWG based mixtures according to the mixture design presented in Table 3. Ingredients of the mixtures were first dry mixed in a pan mixer for 5 minutes. After that, water was added and further mixing was carried out until homogeneous mixtures were obtained. Mixtures were then transferred to casting unit and poured into molds and compressed with hydraulic compressor. CMU were demolded after $24 \mathrm{hrs}$. and stored in curing tank until their age of testing.

\subsubsection{Fresh Mixture Properties}

Standard consistency and setting times and flow characteristics of the fresh, normal and PWG-based mixtures were evaluated and are shown in Table 4 . In the preliminary testing, the flow characteristics of the PWG mixture produced with $15 \mathrm{wt} \% \%$ replacement of cement with glass were found to be convenient for the production of CMU.

\subsubsection{Compressive Strength Tests of CMU}

All of the normal and PWG based CMU were tested in compression after curing in water. Upon completion of the curing period, specimens were taken out of curing tank one day prior to the testing and allowed to dry. Specimens were then capped with Hydrastone plaster and tested in compression. For each mixture two replicates were produced and each of the test reading is the average of 
three test readings.

\subsubsection{Cumulative Water Absorption Test}

Water absorption of CMU was determined according to the provisions of ASTM C-1585 for normal and PWG based mixtures. After demolding, the CMU were first saturated according to ASTM C1202 and then conditioned by placing them in environmental chamber for three days at a temperature of $50^{\circ} \mathrm{C}$ and relative humidity of $80 \%$. After three days, samples were removed from chamber and their mass readings were recorded. Dimensions of surface to be exposed to water were also measured. All surfaces of samples were sealed with silicon gel except the bottom surface which was to be exposed to water. Mass of sealed samples was recorded and then placed in a pan having water in it so that sample surface is $2 \mathrm{~mm}$ below the water level. Saturated mass of the CMU were recorded at prescribed intervals until 42 days.

\subsubsection{Dry Density}

Dry density of normal and PWG based CMU was determined at mixture ages of 28 and 90 days. The net volume of the CMU blocks was determined using water displacement method. Subsequently, dry density was calculated as mass of the CMU over the net volume.

Table 2. Chemical composition of glass and cement

\begin{tabular}{ccccccccc}
\hline Material & $\mathbf{S i O}_{2}$ & $\mathbf{N a}_{2} \mathbf{O}$ & $\mathbf{C a O}$ & $\mathbf{A l}_{2} \mathbf{O}_{3}$ & $\mathbf{M g O}$ & $\mathbf{K}_{2} \mathbf{O}$ & $\mathbf{F e}_{2} \mathbf{O}_{3}$ & $\mathbf{L O I}$ \\
\hline PWG & $73 \%$ & $9.5 \%$ & $8.5 \%$ & $7.3 \%$ & $0.7 \%$ & $<1 \%$ & $<1 \%$ & $0.5 \%$ \\
\hline Cement & $20.5 \%$ & $0.40 \%$ & $65.25 \%$ & $6.25 \%$ & $2.25 \%$ & $0.5 \%$ & $2.5 \%$ & $2.4 \%$ \\
\hline
\end{tabular}

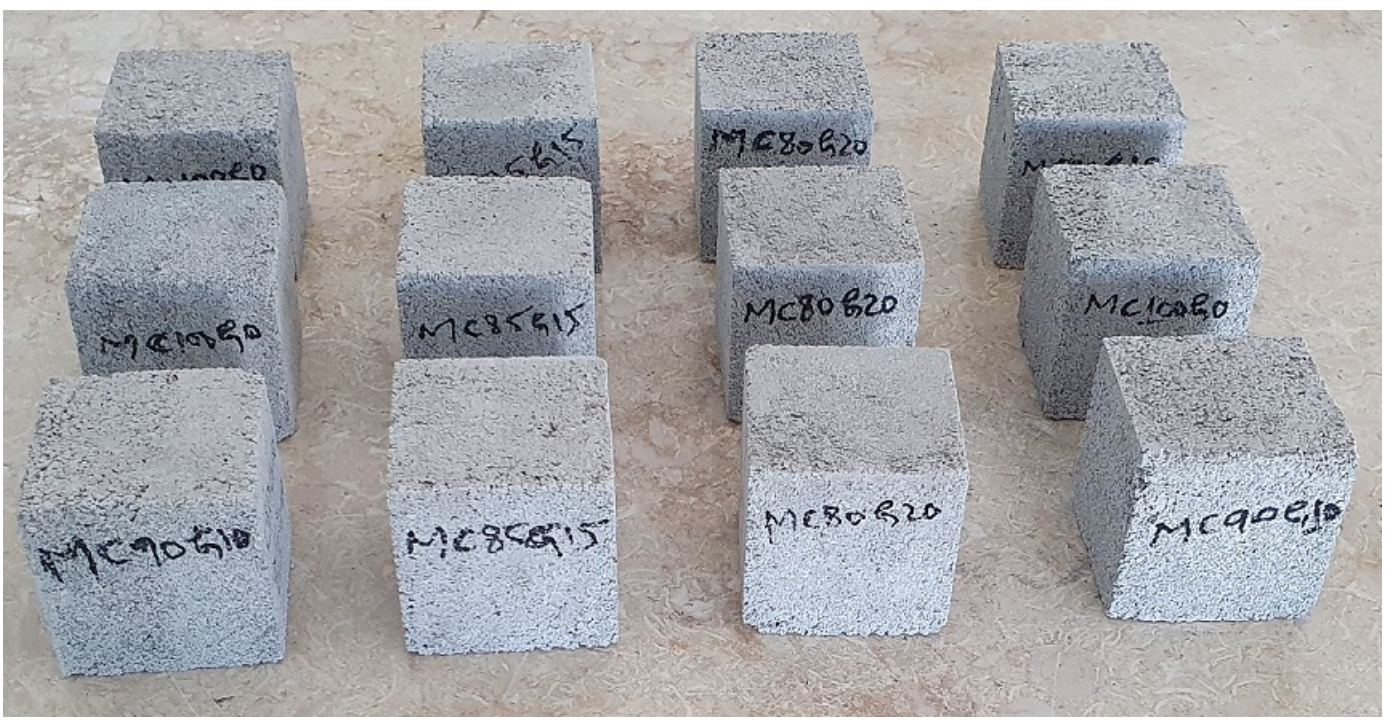

Figure 2. View of the mortar specimens produced in the preliminary testing

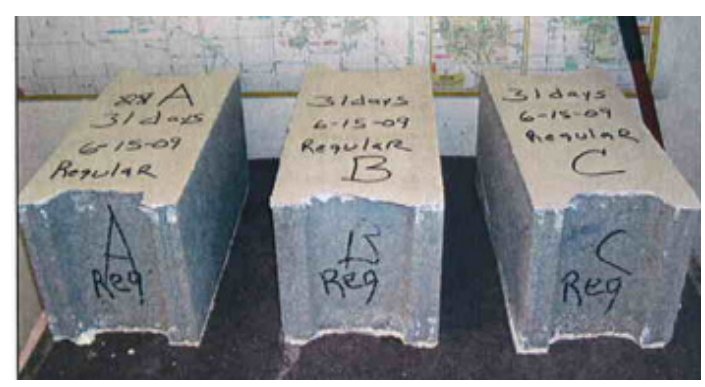

(a)

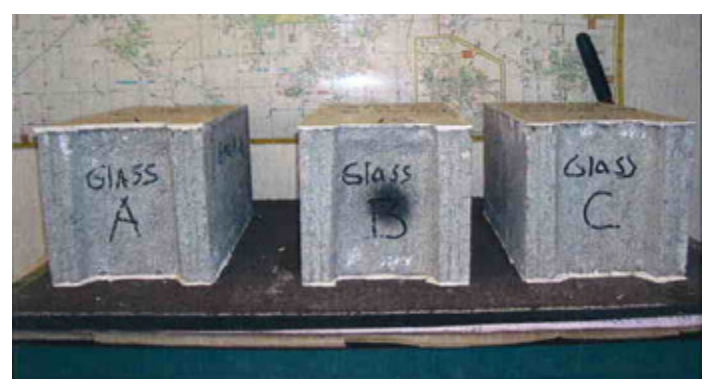

(b)

Figure 3. Views of CMU produced in the experimental program: (a) normal (b) PWG

Table 3. Mixture designs

\begin{tabular}{ccccc}
\hline $\begin{array}{c}\text { Mixture } \\
\text { type }\end{array}$ & $\begin{array}{c}\text { Cement to aggregate } \\
\text { ratio }\end{array}$ & $\begin{array}{c}\text { Water to cementitious material } \\
\text { ratio }\end{array}$ & $\begin{array}{c}\text { Water reducing } \\
\text { agents }\end{array}$ & $\begin{array}{c}\text { \% Replacement of cement with } \\
\text { glass }\end{array}$ \\
\hline Normal & $1: 8$ & 0.24 & $1.95 \mathrm{ml} / \mathrm{kg}$ of cement & 0 \\
\hline PWG & $1: 8$ & 0.24 & $2.0 \mathrm{ml} / \mathrm{kg}$ of cement & 15 \\
\hline
\end{tabular}


Table 4. Fresh mortar properties

\begin{tabular}{ccccc}
\hline Mixture type & $\begin{array}{c}\text { Standard Consistency } \\
(\%)\end{array}$ & $\begin{array}{c}\text { Initial setting time } \\
(\mathbf{m i n})\end{array}$ & Final setting time (min.) & Mortar Flow (mm) \\
\hline Normal & 26.9 & 116 & 215 & 114 \\
\hline PWG & 25 & 141 & 240 & 108 \\
\hline
\end{tabular}

\section{Results and Discussions}

\subsection{Compressive Strength of the Mortar Mixtures}

Figure 4 presents the compressive strength test results for mortar specimens. It is noted that the $15 \mathrm{wt} . \%$ PWG mixture produced higher compressive strength as compared to that of the $25 \mathrm{wt} . \%$ PWG mixture at all testing ages. Although both of the PWG-based mixtures show lower strength as compared to that of normal mixture, at later age (28 days), the compressive strength of $15 \mathrm{wt} . \%$ PWG mixture is comparable to that of normal mixture's compressive strength. These results confirm the findings of previously published studies $[26,38,39]$. Due to the slow nature of the pozzolanic reaction of PWG with the hydrates of cement, these mixtures develop later age strength which is comparable or even higher than that of the normal mixture strength. A significant gain in compressive strength at 90 days of age of mixture produced by partially replacing cement with milled glass has been reported in earlier studies as well [40].

\subsection{Standard Consistency, Setting Time, and Mortar Flow}

Results of standard consistency, setting time and mortar flow tests are presented in Table 4.

Standard consistency of cementitious mix tends to slightly decrease with the inclusion of PWG. Furthermore, the presence of PWG is seen to delay the initial and final setting times of the resulting cementitious paste. The increase in the setting times and slight reduction in consistency of the PWG-based mixture may be the result of the dilution effect caused by inclusion of PWG in the mixture. Decrease in mortar flow as result of inclusion of PWG may be the result of the loss of moisture in the mixture due to the presence of the tiny PWG particles noting that the average particle size of the PWG used in this experimental program is considerably smaller than that of cement. The smaller particle size of PWG consequently results into increase in the surface area of the material causing a loss of moisture in the cementitious system and a decrease in the flow of mortar. The decrease in mortar flow characteristics caused by PWG confirms the finding of the earlier researchers as well [41].

\subsection{Compressive Strength of CMU}

Results of compressive strength test of CMU are presented in Figure 5. It is noted that the compressive strength of CMU produced with $15 \mathrm{wt}$ \% replacement of cement with PWG is slightly less than that of the CMU made with control mixture at 28 days of age. This trend is, however, reversed at the age of 56 days wherein the PWG mixture CMU achieves about $13 \%$ higher strength than that of control CMU. Similar results are observed at 90 days of mixtures age wherein the PWG-based CMU show about $12 \%$ higher strength than that of control CMU. The increase in the later-age strength of the PWG-based CMU higher than that of the control CMU is thought to be the effect of the pozzolanic reaction of the PWG with the hydrates of cement which results into pore filling effect caused by the production of secondary calcium silicate hydrates (C-S-H). The secondary C-S-H is produced through the conversion of calcium hydroxide to C-S-H during the pozzolanic reaction. The pore filling effect of PWG ultimately results into densification of the cementitious microstructure and hence increases in compressive strength of the CMU. The ability of PWG to undergo pozzolanic reaction and the consequent microstructure refinement of the resulting mixture has been reported in some earlier studies as well $[39,42,43]$. Above test results suggest that cement can be replaced at $15 \mathrm{wt} . \%$ with PWG for the production of CMU with enhanced compressive strength characteristics. The PWG-based CMU shall be an eco-friendly production of masonry units resulting into reducing the carbon foot prints of the masonry construction.

\subsection{Water Absorption}

The eight-day cumulative water sorption test results of normal and PWG-based CMU are shown in Figure 6. The PWG-based CMU blocks showed significantly lower moisture sorption as compared to that of normal CMU. After 8 days of continuous exposure to moisture, about $43 \%$ reduction in cumulative moisture sorption was recorded for the PWG-based CMU as compared to that of normal CMU. This reduction in water sorption can be attributed to microstructure improvement of cementitious matrix brought about by the inclusion of PWG in the mixture. The pore filling and pore refinement effect caused by the PWG results in significantly enhancing the moisture barrier characteristics of the resulting mixture and hence reduction in the moisture absorption. This finding confirms the outcome of some of the earlier studies [44]. It is to be noted that the improvement in moisture barrier characteristics significantly improves the durability of the cementitious materials as most of the durability issues in cement-based materials are caused by the moisture 
transport into these materials which carry with them deleterious ions [45, 46]. Enhanced durability of the PWG-based CMU means that their use in masonry construction will result into the longevity of the service life of the relevant structures.

\subsection{Dry Density of Hardened CMU}

Density of hardened normal and PWG-based CMU blocks at 28 and 90 days of mixtures ages is presented in Figure 7. The inclusion of $15 \mathrm{wt} . \%$ PWG resulted in about $10 \%$ reduction in the dry density of the PWG-based CMU in comparison to that of normal CMU. The reduction in dry density of PWG-based CMU may be explained based on the lower specific gravity of the PWG as compared to that of Portland cement. The reduction in dry density of the CMU will result into reduction in the dead load on the masonry structure which eventually will require the design of various structural members with smaller geometric dimensions. It can therefore be stated that the use of PWG-based CMU will result in the construction of economical masonry construction: firstly; through use of less cement in the mixture and secondly; through considerable reduction in the dead load of the structure.

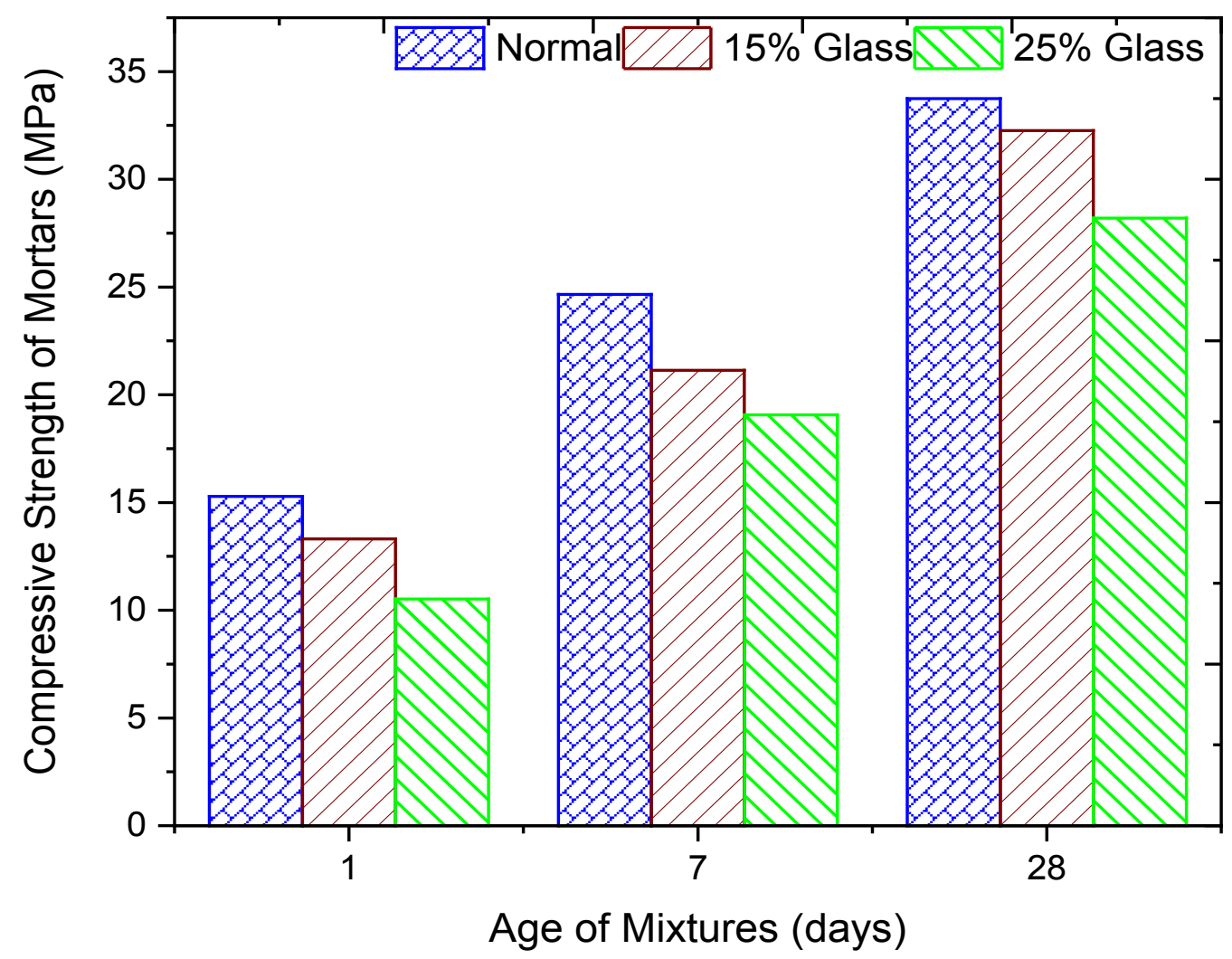

Figure 4. Compressive strength test results of mortar mixtures 




Figure 5. Compressive strength test results of CMU



Figure 6. Eight days cumulative water sorption test results of normal and PWG-based CMU 


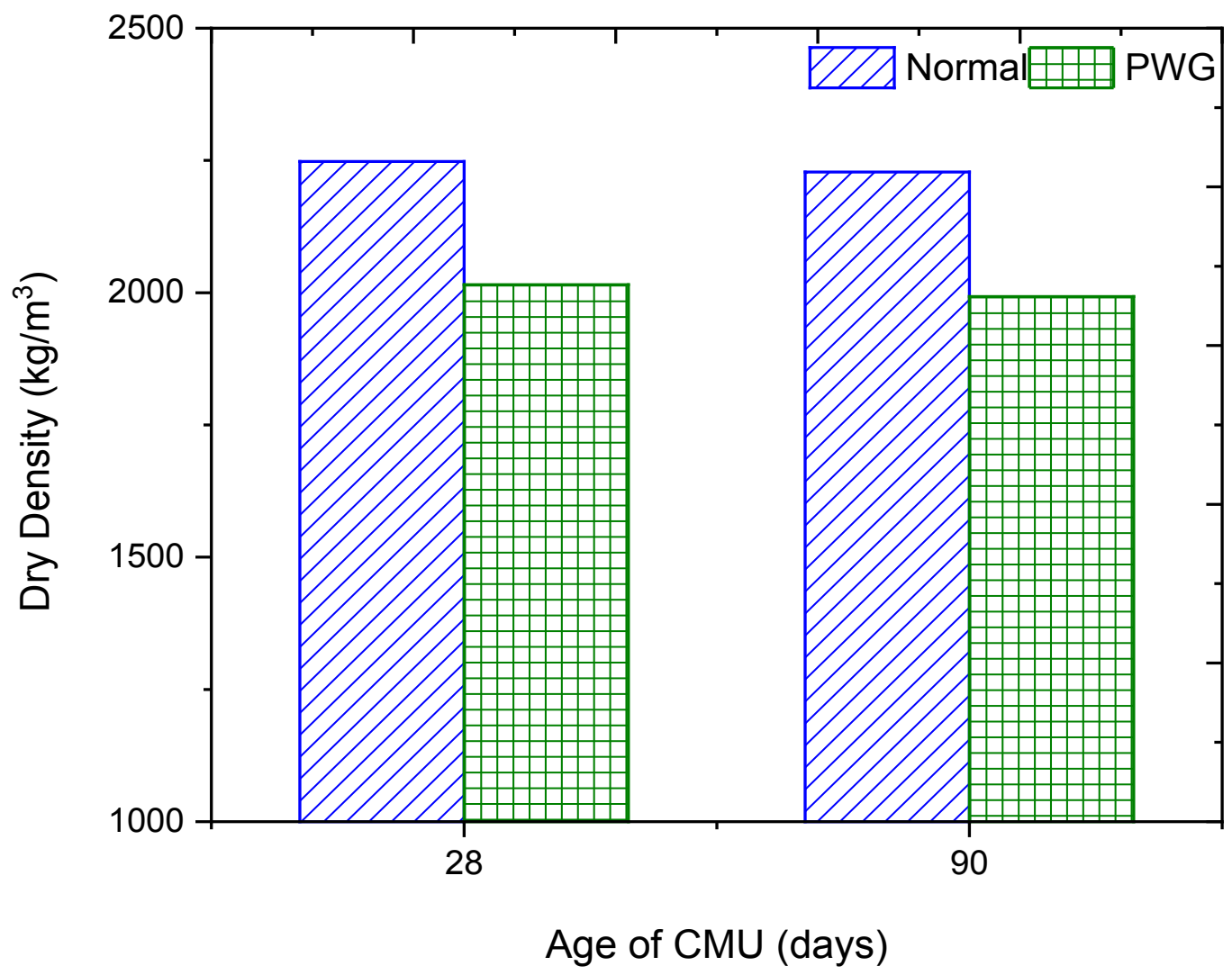

Figure 7. Dry density test results of normal and PWG-based CMU

\section{Conclusions}

Based on the outcome of the experimental results of this study, following conclusions are drawn:

1. Partial replacement of cement with PWG resulted in production of CMU that have enhanced strength and durability as compared to that of the normal CMU. The use of $15 \mathrm{wt} . \%$ of PWG as cement replacement resulted into 13 and $12 \%$ increase in compressive strength of CMU at 56 and 90 days of mixture ages, respectively as compared to that of CMU made of normal (control) mixture. The improvement in the strength and durability characteristics of CMU are brought about by the microstructure improvement of the hardened cementitious mixture caused by the pore filling effect and pozzolanic reaction of PWG with the hydrates of cement.

2. The use of PWG as partial replacement of cement (at 15 wt.\%) towards production of CMU resulted into huge reduction in their water sorption characteristics pointing at the enhancement of their durability attribute brought about by the pore refinement effect of PWG through its pozzolanic reaction. It is to be mentioned that the improvement in moisture barrier characteristics of the CMU produced with PWG will have significantly enhanced service life, noting that most of the deteriorations in hardened cementitious mixtures are caused by the ingress of water in these materials.

3. About $10 \%$ reduction in the dry density of hardened CMU realized through $15 \mathrm{wt}$ \% replacement of cement with PWG, is viewed as an important achievement towards economizing the construction of built infrastructure as the significant reduction in the self-weight of masonry structure will allow to design structural members with smaller geometric cross sections.

4. The use of PWG for the production of CMU blocks is a viable practice that has significant environmental benefits and is in line with the principles of sustainability towards an eco-friendly construction of civil infrastructure.

5. A numerical quantification of the reduction in $\mathrm{CO}_{2}$ emissions and cost of masonry achieved through the replacement of $15 \mathrm{wt} . \%$ cement with PWG towards production of $\mathrm{CMU}$, will be a good topic for future investigation.

\section{REFERENCES}

[1] Pacheco-Torgal, F., 1 - Introduction to eco-efficient masonry bricks and blocks, in Eco-Efficient Masonry Bricks and Blocks, F. Pacheco-Torgal, et al., Editors. 2015, 
Woodhead Publishing: Oxford. p. 1-10.

[2] Fernandes F.M., L.P.B., Castro F., Ancient Clay Bricks: Manufacture and Properties. Materials, Technologies and Practice in Historic Heritage Structures., ed. P.R. Dan M.B., Török Á. 2010: Springer, Dordrecht.

[3] PCA, Concrete Masonry Units. 2020, Portland Cement Association: Skokie, Illinois USA.

[4] Venkatarama Reddy, B.V. and K.S. Jagadish, Embodied energy of common and alternative building materials and technologies. Energy and Buildings, 2003. 35(2): p. 129-137.

[5] Chen, W., et al., Embodied energy and carbon emissions of building materials in China. Building and Environment, 2022. 207: p. 108434.

[6] Best, R.d., Annual production of concrete blocks in Great Britain 2007-2020. 2021, Statista: UK.

[7] Linker, R., Global Concrete Block and Brick Manufacturing Industry. Nov 2020. p. 187.

[8] Al-Fakih, A., et al., Incorporation of waste materials in the manufacture of masonry bricks: An update review. Journal of Building Engineering, 2019. 21: p. 37-54.

[9] Horpibulsuk, S., et al., Strength of sustainable non-bearing masonry units manufactured from calcium carbide residue and fly ash. Construction and Building Materials, 2014. 71: p. $210-215$.

[10] Meng, Y., T.-C. Ling, and K.H. Mo, Recycling of wastes for value-added applications in concrete blocks: An overview. Resources, Conservation and Recycling, 2018. 138: p. 298-312.

[11] Kumar, P.M., Reducing the Environmental Impact of Concrete. Concrete International. 23(10).

[12] Mehta, P.K., Greening of the Concrete Industry for Sustainable Development. Concrete International. 24(7).

[13] Meyer, C., Concrete Materials and Sustainable Development in the USA. Structural Engineering International, 2004. 14(3): p. 203-207.

[14] Canada, C.A.o., Annual global production of concrete. 2018.

[15] Jannat, N., et al., Utilization of nut shell wastes in Brick, Mortar and Concrete: A review. Construction and Building Materials, 2021. 293: p. 123546.

[16] Nations, U., Peace, dignity and equality on a healthy pla. 2020, United Nations.

[17] IEA, Technology Roadmap - Low-Carbon Transition in the Cement Industry, in Cement Sustainability Initiative. 2018, International Energy Agency. p. 66.

[18] Association, W.C., Despite Progress During 2018, Reducing Carbon Footprint Remains a Challenge for the Cement Industry. 2019: October 25, 2019.

[19] Costa, F.N. and D.V. Ribeiro, Reduction in $\mathrm{CO}_{2}$ emissions during production of cement, with partial replacement of traditional raw materials by civil construction waste $(C C W)$. Journal of Cleaner Production, 2020. 276: p. 123302.
[20] Faheem, A., S.A. Rizwan, and T.A. Bier, Properties of self-compacting mortars using blends of limestone powder, fly ash, and zeolite powder. Construction and Building Materials, 2021. 286: p. 122788.

[21] Henry, C.S. and J.G. Lynam, Embodied energy of rice husk ash for sustainable cement production. Case Studies in Chemical and Environmental Engineering, 2020. 2: p. 100004 .

[22] Soroushian, P., Strength and durability of recycled aggregate concrete containing milled glass as partial replacement for cement. Construction and Building Materials, 2012. 29: p. 368-377.

[23] Mehta, P.K., Global Concrete Industry Sustainability. Concrete International. 31(2).

[24] Reis, D.C., et al., Influence of cement strength class on environmental impact of concrete. Resources, Conservation and Recycling, 2020. 163: p. 105075.

[25] Castañeda, D., et al., Production of a lightweight masonry block using alkaline activated natural pozzolana and natural fibers. Construction and Building Materials, 2020. 253: p. 119143.

[26] Nassar, R.-U.-D. And P. Soroushian, Green and durable mortar produced with milled waste glass. Magazine of concrete research, 2012. 64(7): p. 605-615.

[27] Esmaeili, J. and A. Oudah Al-Mwanes, A review: Properties of eco-friendly ultra-high-performance concrete incorporated with waste glass as a partial replacement for cement. Materials Today: Proceedings, 2021. 42: p. 1958-1965.

[28] Guo, P., et al., New perspectives on recycling waste glass in manufacturing concrete for sustainable civil infrastructure. Construction and Building Materials, 2020. 257: p. 119579.

[29] Islam, G.M.S., M.H. Rahman, and N. Kazi, Waste glass powder as partial replacement of cement for sustainable concrete practice. International Journal of Sustainable Built Environment, 2017. 6(1): p. 37-44.

[30] EPA, U.S., Glass: Material-Specific Data, in Facts and Figures about Materials, Waste and Recycling. 2020, United States Environmental Protection Agency https://www.epa.gov/facts-and-figures-about-materials-wa ste-and-recycling/glass-material-specific-data.

[31] Nassar, R.-U.-D. and Soroushian, P., Use of milled waste glass in recycled aggregate concrete. Proceedings of the Institution of Civil Engineers - Construction Materials, 2013. 166(5): p. 304-315.

[32] Nassar, R-U-D., Soroushian, P., Field investigation of concrete incorporating milled waste glass. JOURNAL OF SOLID WASTE TECHNOLOGY AND MANAGEMENT, 2011. 37(4): p. 307-319.

[33] Shayan, A. and A. Xu, Value-added utilisation of waste glass in concrete. Cement and Concrete Research, 2004. 34(1): p. 81-89.

[34] Omer, B. and Saeed, J., Characterizations and modeling the influence of particle size distributions (PSD) of glass powder on the mechanical behavior of normal strength concrete. Civil Engineering and Architecture, 2020. 8(5), p. 993 - 1005. DOI: 10.13189/cea.2020.080526. 
[35] Shayan, A. and A. Xu, Performance of glass powder as a pozzolanic material in concrete: A field trial on concrete slabs. Cement and Concrete Research, 2006. 36(3): p. 457-468.

[36] Nassar, R.-U.-D., P. Soroushian, and M. Sufyan-Ud-Din, Long-term field performance of concrete produced with powder waste glass as partial replacement of cement. Case Studies in Construction Materials, 2021. 15: p. e00745.

[37] Balasubramanian, B., et al., Experimental investigation on concrete partially replaced with waste glass powder and waste E-plastic. Construction and Building Materials, 2021. 278: p. 122400.

[38] Patel, D., et al., Effective utilization of waste glass powder as the substitution of cement in making paste and mortar. Construction and Building Materials, 2019. 199: p. 406-415.

[39] Aliabdo, A.A., M. Abd Elmoaty, and A.Y. Aboshama, Utilization of waste glass powder in the production of cement and concrete. Construction and Building Materials, 2016. 124: p. 866-877.

[40] Nahi, S., et al., Properties of cement pastes and mortars containing recycled green glass powder. Construction and Building Materials, 2020. 262: p. 120875.

[41] Parghi, A. and M.S. Alam, Physical and mechanical properties of cementitious composites containing recycled glass powder (RGP) and styrene butadiene rubber (SBR). Construction and Building Materials, 2016. 104: p. 34-43.

[42] Higuchi, A.M.D., et al., Use of glass powder residue as an eco-efficient supplementary cementitious material. Construction and Building Materials, 2021. 304: p. 124640.

[43] Olutoge, F., Effect of waste glass powder (WGP) on the mechanical properties of concrete. American Journal of Engineering Research, 2016. 5(11): p. 213-220.

[44] Raju, A.S., K.B. Anand, and P. Rakesh, Partial replacement of Ordinary Portland cement by LCD glass powder in concrete. Materials Today: Proceedings, 2020.

[45] Mehta, P. K. M., P. J. M., Concrete: Microstructure, Properties, and Materials 4th ed. 2014, United States: McGraw Hill Education.

[46] Neville, A.M., Properties of Concrete. 2011, England: Pearson Education Limited. 